\title{
A PERCEPÇÃO DOS ENFERMEIROS SOBRE O SEU PAPEL NOS CONSELHOS DE SAÚDE ENQUANTO SEGMENTO DOS TRABALHADORES DE SAÚDE
}

Juliana Chagas da Silva Mittelbach'1, Paulo de Oliveira Perna²

1Enfermeira. Universidade Federal do Paraná. Curitiba-PR-Brasil.

${ }^{2}$ Enfermeiro. Mestre em Enfermagem. Universidade Federal do Paraná. Curitiba-PR-Brasil.

RESUMO: O estudo objetiva analisar o conhecimento e percepções dos enfermeiros sobre seu papel no Controle Social e identificar aspectos que limitam e que fazem avançar a sua participação nos Conselhos de Saúde, enquanto trabalhadores de saúde. Os preceitos éticos em pesquisa foram observados. Constatou-se que os enfermeiros, acertadamente, entendem o Controle Social como a participação da sociedade nas políticas públicas. Todavia, enquanto trabalhadores, estes profissionais não vêem como força capaz de influenciar nas políticas públicas em favor, por exemplo, dos interesses dos trabalhadores de saúde e da população. Como explicações dessas limitações foram citados, com destaque, a falta de interesse pela ação política em geral e também a dupla jornada de trabalho como consumidora do tempo. Por sua vez, foram apontados aspectos que avançam a participação, aparecendo com relevância o aumento da quantidade de pessoal de saúde e a formação mais adequada do Enfermeiro, que tem enfocado a dimensão sociopolítica.

DESCRITORES: Participação Social; Enfermeiro; Sistema Único de Saúde; Conselhos de Saúde.

\section{NURSES' PERCEPTION ON THEIR ROLE IN THE HEALTH COUNCILS AS A SEGMENT OF THE HEALTH WORKERS}

\begin{abstract}
This study analyzes nurses' knowledge and perceptions regarding their role in Social Control, and identifies aspects which limit and advance their participation in the Health Councils as health workers. Contact was made with 18 nurses working in nine Health Districts of the Curitiba Municipal Health Department, between January and July 2012. It was observed that the nurses understand Social Control as society's participation in public policies. However, as workers, these professionals do not see themselves as a force capable of influencing public policies in favor of their own interests as workers, or in favor of those of the population. The following were mentioned as explanations for these limitations: lack of interest in politics and working two shifts per day. In addition, aspects were indicated which advance participation, with the increase in the number of health personnel and the more appropriate training of the Nurse, focusing on the sociopolitical dimension, appearing with relevancy.
\end{abstract}

DESCRIPTORS: Social Participation; Nurse; Unified Health System; Health Councils.

\section{LA PERCEPCIÓN DE LOS ENFERMEROS SOBRE SU PAPEL EN LOS CONSEJOS DE SALUD COMO SEGMENTO DE LOS TRABAJADORES DE SALUD}

RESUMEN: El estudio analiza el conocimiento y las percepciones de los enfermeros sobre su papel en el Control Social e identifica aspectos que limitan y que llevan a progredir su participación en los Consejos de Salud, como trabajadores de salud. Fueron abordados dieciocho enfermeros de nueve Districtos Sanitarios de la Secretaria Municipal de Salud de Curitiba, de enero a julio de 2012. Se constató que los enfermeros entienden el Control Social como participación de la sociedad en las políticas públicas. Todavía, como trabajadores, estes profesionales no se miran como fuerza capaz de influenciar en las políticas públicas en favor de los propios intereses como trabajadores, así como los de la población. Como explicaciones de esas limitaciones, fueron mencionadas: la falta de interés por la política y la doble jornada laboral. Fueron indicados, también, aspectos que estimulan la participación, siendo apuntados con relevancia el aumento de la cuantidad de personal de salud y la formación más adecuada del enfermero, enfocando la dimensión sociopolítica. DESCRIPTORES: Participación social; Enfermero; Sistema Único de Salud; Consejos de Salud.

Universidade Federal do Paraná

Rua João Bettega, 644 - 81070-000 - Curitiba-PR-Brasil

E-mail: juzinhachagas@gmail.com 


\section{INTRODUÇÃO}

Entende-se que a participação política é condição indispensável à construção e defesa do Sistema Único de Saúde (SUS), e de que a classe trabalhadora tem lugar central na definição desse processo, sendo este um dos princípios nucleares na estruturação do SUS, conforme a Carta Constitucional de 1988. Trata-se do controle social (CS), sem o qual, os riscos de distanciamentos e obstáculos à realização dos direitos civis são bastante prováveis, dado o caráter classista da sociedade brasileira, em que a classe trabalhadora deve permanentemente fazer valer seus direitos ${ }^{(1)}$.

O exercício do CS é um dos campos de ação política que deu visibilidade aos movimentos sociais, quer pela denúncia das ausências e omissões do Estado, quer pela luta em constituir um espaço regular para o exercício do controle da burocracia própria da gestão estatal(2). Os enfermeiros estão praticamente presentes em todos os serviços de saúde, têm lugar privilegiado para comunicar-se com a população e impulsionar a exigência por uma assistência de maior qualidade ${ }^{(3)}$. Os enfermeiros que atuam em Unidade Básica de Saúde (UBS), em especial, estão em contato direto com usuários de variadas procedências e podem desempenhar um papel estratégico articulador entre os anseios daqueles e o processo de produção das ações de saúde ${ }^{(4)}$.

Os processos de trabalho se configuram como um dos grandes nós críticos do modelo tecnoassistencial em saúde no Brasil, "que se tem mostrado comprometido com muitos tipos de interesse, exceto com a saúde dos cidadãos ${ }^{\prime \prime(5: 71-72) . ~}$ Uma das características que garante ao SUS sua singularidade é que a participação de usuários e trabalhadores de saúde popular não foi reivindicada apenas para se manifestar sobre avaliações do grau de satisfação, ou para participar em ações comunitárias, mas para tomar decisões em caráter deliberativo sobre a política pública de saúde.

Além da própria participação no CS, enquanto educador em saúde, cada enfermeiro pode envidar esforços para estimular a população sobre o caráter necessário e político de sua participação no CS. No entanto, para educar com propriedade, é necessário que este profissional tenha formação adequada, sendo capaz de avaliar as contradições próprias do jogo político, e com isso nem alimentar ufanismos, mas também não esmorecer com os reveses sofridos, desacreditando das possibilidades de mudanças. Sobre isso, nunca é demais salientar que a formação dos profissionais de saúde ainda tem permanecido débil sobre esse tema. As instituições formadoras perpetuam modelos de ensino em saúde acríticos, essencialmente conservadores, centrados na doença, dando ênfase às tecnologias altamente especializadas, reforçando a dependência progressiva de procedimentos/equipamentos de apoio diagnóstico e terapêutico ${ }^{(6-7)}$. Assim, as análises de ordem político-econômicas ficam muito distantes, quando não ausentes, reproduzindo as dificuldades do futuro profissional de avaliar, em bases concretas, a estruturação do cuidado em sociedades desiguais, bem como as medidas sociais para seu enfrentamento.

Em uma sociedade de classes, questões relacionadas ao poder e ao conhecimento continuam presentes, dificultando a participação dos desiguais. Uma série de obstáculos ainda se fazem presentes para o CS no Brasil, em função de uma história política caracterizada por regimes centralizadores e autoritários, que afastaram e continuam afastando os trabalhadores dos processos de tomada de decisão(8). No Brasil, em especial a partir dos anos 90, a assunção de governos assumidamente neoliberais, legitimou de vez uma das marcas mais nefastas daquela forma de compreensão da constituição social: o individualismo. Sustentada na premissa de que o mercado é o verdadeiro espaço livre, e onde os indivíduos devem aparecer e realizar suas capacidades empreendedoras, e com isso construir sociedades sólidas e democráticas, o espaço público tende a ser desmerecido ou encolhido ao máximo possível ${ }^{(9)}$. Neste cenário, a proposta de CS, de fato, vai encontrar muitos obstáculos à sua realização.

No entanto, Antonio Gramsci ensina que não se deve entender sociedade civil e Estado como entes em oposição necessária, mas em relação dialética:

A sociedade civil é duplo espaço de luta de classes: expressa contradições e ajustes entre frações da classe dominante e, ao mesmo tempo, nela se organizam também as lutas entre as classes ${ }^{(10: 373)}$.

Com essa premissa, o CS se apresenta como possibilidade de luta para a quebra dos aparelhos 
privados de hegemonia e mudança nas formas e graus de dominação.

Com estas premissas, o presente estudo buscou analisar o conhecimento e percepções dos enfermeiros de UBS do município de Curitiba sobre o seu papel no CS da política pública de saúde e identificar aspectos que os enfermeiros entendem que limitam e/ou que fazem avançar a sua participação no CS enquanto segmento de trabalhadores.

\section{MÉTODO}

Os elementos teórico-metodológicos que balizaram esta pesquisa são do materialismo histórico-dialético, levando em conta as contradições e os conflitos do contexto histórico e social no qual o objeto de estudo - o CS - se expressa. Assim, a pesquisa buscou apreender tanto os aspectos qualitativos e quantitativos ligados ao objeto, dado que o real, em sua totalidade, não pode prescindir desses dois âmbitos ${ }^{(11)}$. A pesquisa também teve um caráter exploratório, compreendendo estudo bibliográfico e entrevistas ${ }^{(12)}$.

Os sujeitos foram enfermeiras(os) atuantes em UBS dos nove Distritos Sanitários de Curitiba. Critério de exclusão: ficaram de fora enfermeiros que estavam ocupando cargo de chefia e que, nessa posição supostamente representavam os interesses do gestor municipal nos Conselhos de Saúde. Critério de inclusão: o único critério de inclusão do participante era ter graduação em Enfermagem. Os participantes foram identificados pelo codinome Enf.1 à Enf.18.

As entrevistas ocorreram de janeiro a julho de 2012, de acordo com roteiro estruturado, com questões abertas, sendo gravadas, degravadas e, posteriormente, desgravadas. A pesquisa respeitou a Res. 196/96 CNS/MS e foi aprovada nos Comitês de Ética em Pesquisa da Universidade Federal do Paraná, bem como da Secretaria Municipal de Saúde de Curitiba. Aos participantes foi solicitado assinar o Termo de Consentimento Livre e Esclarecido.

Em cada Distrito Sanitário foram escolhidas, através de sorteio, duas UBS, sendo que em cada uma delas foi entrevistada apenas um enfermeiro, num total de 18 enfermeiros, escolhidos também de forma aleatória. Considerou-se que tal procedimento garantiria abarcar a diversidade e variabilidade do objeto estudado.

\section{RESULTADOS}

Após exploração do material e seleção das unidades de análise, os dados foram categorizados nos seguintes temas: "Conceito dos enfermeiros sobre o que é Controle Social"; "Atuação dos enfermeiros no CS"; "Limites para a participação dos Enfermeiros no CS"; "Avanços na participação dos Enfermeiros no CS" e "Influência dos Enfermeiros nos Conselhos Locais sobre o trabalho da Enfermagem". Em alguns casos, como se observa nas tabelas, foi considerada mais de uma resposta por enfermeiro.

Os profissionais avaliaram positivamentea atuação dos Conselhos de Saúde (Tabela 1), caracterizandoos como espaços de debate e de politização.

Tabela 1 - Conceito dos enfermeiros sobre controle social. Curitiba-PR-Brasil, 2012

\begin{tabular}{|c|c|c|}
\hline Conceitos & $n$ & $\%$ \\
\hline $\begin{array}{l}\text { Forma de participação da } \\
\text { sociedade na melhoria do } \\
\text { Sistema Único de Saúde }\end{array}$ & 10 & 28 \\
\hline $\begin{array}{l}\text { Forma de participação da } \\
\text { comunidade nas ações e } \\
\text { políticas de saúde }\end{array}$ & 04 & 11 \\
\hline $\begin{array}{l}\text { Instância de construção de } \\
\text { políticas de saúde }\end{array}$ & 03 & 08 \\
\hline $\begin{array}{l}\text { Forma de participação da } \\
\text { sociedade em leis orgânicas } \\
\text { da saúde e em movimentos } \\
\text { sociais em favor da saúde }\end{array}$ & 01 & 03 \\
\hline $\begin{array}{l}\text { Espaço de acordo entre gestor } \\
\text { e usuários }\end{array}$ & 18 & 50 \\
\hline Total & 36 & 100 \\
\hline
\end{tabular}

Cabe registrar que apenas uma enfermeira entendeu ser o CS uma ação que não se encerra nas formas institucionais - Conselhos, Conferências, etc. - e que Movimentos Sociais organizados também podem fazer esse papel, mesmo fora dos limites institucionalizados:

\section{O CS é participação da comunidade nas} [formulações das] Leis Orgânicas da Saúde, do SUS mesmo, e em Movimentos em favor da saúde. (Enf. 01)

O entendimento dos enfermeiros sobre sua atuação no Controle Social é mostrado na Tabela 2. 
Tabela 2 - Atuação dos enfermeiros no Controle Social. Curitiba-PR-Brasil, 2012

\begin{tabular}{lcc}
\hline Atuação & $\mathbf{n}$ & $\mathbf{\%}$ \\
\hline $\begin{array}{l}\text { Orientação dos usuários } \\
\text { sobre como devem participar } \\
\text { nas reuniões do Conselho, } \\
\text { explicando a importância e } \\
\text { funcionamento desse espaço. }\end{array}$ & 15 & 83 \\
\hline $\begin{array}{l}\text { Participação nas reuniões dos } \\
\text { Conselhos e Conferências de }\end{array}$ & 02 & 11 \\
Saúde. & 01 & 06 \\
\hline $\begin{array}{l}\text { Apenas fazendo seu papel, } \\
\text { isto é, o de ser um profissional } \\
\text { competente. }\end{array}$ & 01 & 100 \\
\hline Total & 18 & \\
\hline
\end{tabular}

Ilustra-se a posição de um dos profissionais sobre esse ponto, com a seguinte afirmação:

OEnfermeiro deve ser suporte para a comunidade, orientando como participar. O governo não tem interesse na orientação do usuário; tem interesse em manipular o usuário. (Enf. 01)

Os aspectos limitantes assinalados pelos profissionais ouvidos são evidenciados na Tabela 3.

Tabela 3 - Aspectos limitantes para o estímuloà participação dos enfermeiros no ControleSocial. Curitiba-PR-Brasil, 2012

\begin{tabular}{lcc}
\hline Aspectos limitantes & $\mathbf{n}$ & $\mathbf{\%}$ \\
\hline $\begin{array}{l}\text { Falta de interesse pela ação } \\
\text { política }\end{array}$ & 13 & 23 \\
\hline $\begin{array}{l}\text { Falta de pessoal em UBS } \\
\text { distantes ou de pequeno porte }\end{array}$ & 11 & 20 \\
\hline Horário (noturno) das reuniões & 10 & 18 \\
\hline Dupla jornada de trabalho & 10 & 18 \\
\hline $\begin{array}{l}\text { Perda do interesse, por ser } \\
\text { um espaço utilizado pelos } \\
\text { usuários para obter facilidades } \\
\text { ou prestígio pessoal }\end{array}$ & 07 & 12 \\
\hline Comodismo dos profissionais & 05 & 09 \\
\hline Total & 56 & 100 \\
\hline
\end{tabular}

Para ilustrar estas posições, tomam-se os seguintes depoimentos:

A pauta [das reuniões do Conselho] já chega pronta. $O$ assunto já é discutido antes e nós pouco temos o que fazer sobre isso. É tudo "armado"! (Enf. 06)
Não é fácil lutar contra a "máquina". Mesmo sendo trabalhador! A reunião é manipulada, a pauta direcionada. A dupla jornada e a carga horária excessiva dificultam a participação. (Enf. 01)

São sempre as mesmas pessoas [nos Conselhos]. Alguns nem sabem o que estão fazendo. Não tem como não perder o interesse. (Enf. 08)

Os usuários querem resolver questões individuais e utilizar o espaço para pleitear cargos políticos eletivos. (Enf. 18)

Os aspectos que fazem avançar a participação dos enfermeiros no Controle Social são mostrados na Tabela 4.

Tabela 4 - Avanços que permitem uma maior participação dos enfermeiros no ControleSocial. Curitiba-PR-Brasil, 2012

\begin{tabular}{lcc}
\hline Avanços & $\mathbf{n}$ & $\mathbf{\%}$ \\
\hline $\begin{array}{l}\text { Maior número de profissionais } \\
\text { enfermeiros na rede }\end{array}$ & 12 & 52 \\
\hline $\begin{array}{l}\text { Maior politização dos } \\
\text { enfermeiros }\end{array}$ & 06 & 26 \\
\hline $\begin{array}{l}\text { Na UBS em que os profissionais } \\
\text { trabalham não há restrição } \\
\text { para a participação nos } \\
\text { Conselhos Locais }\end{array}$ & 05 & 22 \\
\hline Total & 23 & 100 \\
\hline
\end{tabular}

São exemplos, as seguintes posições:

O enfermeiro está mais politizado, estudando mais. Não tem um bando de bitolado. Estão mais atuantes. (Enf. 09)

Nesta UBS não há dificuldade para a participação, maseu não vou. Porque não quero, mesmo!(Enf. 17)

A Tabela 5 mostra as poucas questões que, na opinião dos profissionais de Enfermagem, foram tema dos Conselhos de Saúde e que tiveram algum impacto sobre o seu trabalho.

Eis algumas falas ilustrando este ponto:

A comunidade reconhece o trabalho da Enfermagem. Eles fazem elogios, mas pedem 
cada coisa!!! Reclamam das cadeiras [...], da pintura [...], das janelas [...], e isso não tem a ver com a gente. (Enf. 10)

Solicitaram [os usuários] rampa de acesso. Ajuda na UBS, mas não interfere no trabalho [da Enfermagem]. (Enf 14)

Pediram posto de vacinação no mercado. (Enf. 16)

Tabela 5 - Questões referidas por enfermeiros como sendo tratadas nos Conselhos Locais de Saúde e com impacto sobre o trabalho da Enfermagem. Curitiba-PR-Brasil, 2012

\begin{tabular}{lcc}
\hline Questões e impacto & $\mathbf{n}$ & $\mathbf{\%}$ \\
\hline $\begin{array}{l}\text { Solicitação de pessoal para } \\
\text { segurança (Guarda Municipal) }\end{array}$ & 09 & 50 \\
\hline $\begin{array}{l}\text { Solicitação de reformas } \\
\text { [físicas] na UBS }\end{array}$ & 05 & 27 \\
\hline $\begin{array}{l}\text { Solicita çã o de ma is } \\
\text { profissionais de Enfermagem } \\
\text { para a UBS }\end{array}$ & 02 & 11 \\
\hline $\begin{array}{l}\text { Definição de pontos para } \\
\text { vacinação externa à UBS, em } \\
\text { períodos de campanha }\end{array}$ & 01 & 06 \\
\hline $\begin{array}{l}\text { Solicitação de construção de } \\
\text { rampadeacessoaportadores de } \\
\text { necessidades especiais na UBS }\end{array}$ & 01 & 06 \\
\hline Total & 18 & 100 \\
\hline
\end{tabular}

\section{DISCUSSÃO}

\section{Sobre o conceito dos enfermeiros a respeito do que é Controle Social}

Os profissionais não colocam em destaque o Conselho de Saúde como espaço para tratar das questões dos trabalhadores em saúde, ou seja, de suas próprias questões. Portanto, essa posição permite pressupor que para eles somente os usuários têm problemas para tratar no âmbito do CS, o que revela um reducionismo importante no papel desse espaço.

\section{Sobre a atuação dos enfermeiros no Controle Social}

Os resultados revelam desvalorização ou descrença no poder efetivo do CS, o que já foi, de algum modo, sinalizado anteriormente. A maioria dos profissionais manifestou que o papel do enfermeiro é orientar a participação da população no CS, e também participar ele próprio.

Tais atribuições também foram relatadas em outro estudo ${ }^{(13)}$. É justo afirmar que o profissional tenha tais responsabilidades, porém, estas não seriam as prioridades de sua atuação no CS. É na condição de trabalhador de saúde que ele deve agir politicamente tendo em vista as suas necessidades, uma vez que elas são parte substancial da qualidade final que se espera da assistência. Antes de incentivar a participação dos usuários - o que é importante - a Enfermagem está desafiada a avaliar o potencial estratégico do CS como campo da explicitação de conflitos e contradições que, na cotidianidade dos serviços, tendem a ficar invisibilizados.

Por ser um campo da ação política, a participação também requer um amadurecimento e preparo próprios, com a formação de alianças, explicitação de apoios aos interesses de outros grupos, ponderação de recuos e recusas às pressões. São tais cuidados políticos que vão capacitar o profissional da melhor forma para sua própria atuação e de como orientar os usuários, e não simplesmente "induzi-los" a uma participação para cumprir a prescrição legal.

A natureza contraditória dos Conselhos de Saúde ensina que, apesar de ser uma "extensão" do Estado - portanto, espaços contraditórios, com fortes pressões para servir os interesses dominantes - eles também podem se prestar a ser mais um campo de luta para avançar a melhoria da própria condição de trabalhador de saúde ${ }^{(13)}$. É através da atuação política que se obtém conquistas para a melhoria das condições de trabalho: níveis salariais, carreira pública, desprecarização do trabalho, mecanismos de transparência da gestão pública, espaços de debate de ideias e posições sobre o próprio trabalho, e outros.

\section{Sobre os limites para a participação dos enfermeiros no Controle Social}

A falta de interesse na política confirma a dominância de uma cultura de não-participação, a afirmação do individualismo e a pouca, quando não, ausente consciência política. Esses são aspectos que contribuem para que a atuação 
de trabalhadores nos órgãos colegiados seja reduzida ou com pouco impacto ${ }^{(14)}$. Tal situação resulta, em geral, na incapacidade de influenciar/ contrapor as propostas apresentadas pela Gestão. Não havendo interesse em participação efetiva, a qualificação política do profissional também não é vista como algo necessário, o que acarreta em intervenções pouco eficientes e facilmente contrapostas.

Outro fator relevante encontrado é a cooptação dos representantes de usuários que, muitas vezes, buscam obter favorecimentos e vantagens para si ou grupos próximos. Também ocorre a utilização interessada do representante dos usuários por conta do destaque que o cargo ocupado no Conselho de Saúde lhe dá, podendo servir como trampolim político eleitoral ou alguma vantagem econômica. Enfim, há uma desvalorização da atuação política pelos enfermeiros, tomada como âmbito mais da ação do interesse privado do que o público e, portanto, pouco atrativa e efetiva. Também os profissionais avaliam como mínima a influência do enfermeiro sobre os interesses da Gestão, visto que estes já foram consensuados com outros segmentos.

A dupla jornada de trabalho aparece igualmente como aspecto limitador da participação dos Enfermeiros no CS. Esta situação reflete, de modo geral, a falta de valorização salarial por parte da Gestão que leva o profissional à busca de outras fontes de renda. Esta condição precarizada também vai repercutir na própria capacidade do trabalhador se organizar em torno de suas demandas, já que o tempo para a participação política é consumido integralmente na luta pela existência material.

\section{Sobre os avanços na participação dos enfermeiros no Controle Social}

Em consonância com respostas à questão anterior, o fato que mais recebeu referências foi à disponibilidade de mais profissionais, o que favorece a participação em instâncias de representação política. No período em que a pesquisa foi feita, coincidentemente, a Gestão Municipal estava chamando os aprovados em concurso público e este fato levou os entrevistados a ver uma relação imediata com a resposta à presente questão. Outro aspecto positivo foi creditado à melhor formação política dos profissionais enfermeiros, tanto na graduação como depois de formados.

Neste grupo de resposta, de forma coerente, também houve posições que manifestaram desinteresse pela participação no CS.

\section{Influência dos Enfermeiros nos Conselhos Locais sobre o trabalho da Enfermagem}

O CS pode expressar, de alguma forma, a capacidade que os segmentos, em movimento organizado na sociedade civil, podem ter para interferir na gestão pública, debatendo as ações do Estado (como os gastos financeiro) para favorecer, de forma legítima, seus interesses/necessidades de classe. Apesar das contradições já ressalvadas quanto ao papel dos Conselhos de Saúde, na perspectiva gramsciana, essa participação tem sentido político quando contribui para fazer avançar a construção da hegemonia (ideológica) da classe trabalhadora ${ }^{(15)}$.

Como se avalia pelas respostas, apenas metade dos enfermeiros citou questões referentes à segurança, e bem poucos à melhoria da estrutura física. Para os demais, essas iniciativas não foram associadas a melhorias também para o trabalho da Enfermagem. Ora, a Enfermagem, como tem sido com o trabalhador em geral, vive o dia-a-dia dos entraves de uma estrutura de trabalho inadequada, potencialmente geradora de adoecimento. Isso nos permite comentar que o campo da "saúde do trabalhador" parece estar distante de uma aplicação direta para esses profissionais. No mais, os enfermeiros entrevistados têm o entendimento de que a orientação de gastos públicos em saúde não interfere no trabalho da Enfermagem, visto que alterações estruturais solicitadas, segundo eles, só beneficiariam os usuários.

Avaliadas todas as questões, caberiam, finalmente, alguns comentários de ordem geral. Com base no resultado das entrevistas, pode-se inferir que a posição teórica de Gramsci ${ }^{(16)}$ aplicada sobre o controle social é a que mais se aproxima do que foi encontrado. Tal posição sustenta que a burguesia busca exercer o controle sobre toda a sociedade, não apenas através da coerção política ou econômica, mas, também, pela cooptação ideológica, produzindo uma cultura hegemônica na qual os seus valores (os dela) passem a ser 
também os da sociedade em geral. Esse "senso comum", diz Gramsci, se forma não como uma percepção empírica e passiva da realidade material por parte das pessoas, mas como uma construção mental realizada e introjetada por todo indivíduo, grupo e classe, a partir das ideias dominantes recebidas em vários processos sociais ao longo de sua formação/educação: na escola, na igreja, nos meios de comunicação, etc., ou seja, nas diferentes manifestações do que Marx chama de superestrutura ${ }^{(17)}$.

Os enfermeiros precisam compreender a natureza conflitiva subjacente ao seu trabalho, e a necessidade de fortalecer condições ideológicas para a mudança social, o que implica na mudança de sua própria situação como trabalhadores. Uma visão unitária de mundo desejado pelos trabalhadores é elemento imprescindível para se criar consensos de uma concepção de mundo emancipada. O CS pode cumprir, ao lado de outras manifestações sociais, a proposta de fazer emergir interesses coletivos e comuns, inscrevendo-os no contexto da negociação política.

\section{CONCLUSÃO}

Os resultados trazem contribuições concretas para o tratamento do tema "controle social", enquanto fato que interessa à categoria profissional dos enfermeiros.

Em resposta aos objetivos propostos, o estudo mostrou que enfermeiros de UBS de Curitiba entendem, efetivamente, o CS como uma instância de participação da sociedade no campo da saúde. Todavia, o entendem como uma forma de participação limitada, pois enquanto segmento de trabalhadores da saúde não possui influência na natureza e rumos daquelas políticas em favor dos interesses de seu trabalho profissional. Os enfermeiros reconhecem que seu papel no CS tem sido o da orientação para a participação dos usuários nos Conselhos de Saúde, acreditando mais na eficácia dessa participação do que na sua própria. Pergunta: como "convencer" o outro dos benefícios de algo que não se acredita para si?!

A pesquisa registrou a falta de estímulo dos enfermeiros em representar, nos Conselhos de Saúde, o segmento de trabalhadores. Com esses resultados, portanto, pode-se deduzir que são muitos os desafios da Enfermagem no âmbito da formação política. Urge a necessidade de se levar o profissional a assumir um papel político consistente, para agir no âmbito mais geral da sociedade.

Essa perspectiva, no entanto, exige que os aparelhos formadores enfrentem, por sua vez, o desafio da formação política dos seus professores, entendendo-se que "o próprio educador também precisa ser educado", conforme lembra Marx ${ }^{(18)}$. Ainda no campo da formação de enfermeiros, importa garantir mais espaços para conteúdos da área de Saúde Coletiva, um campo que nasce propriamente da politização das práticas e políticas de saúde, e onde a presente questão é estudada, avaliada e problematizada.

As entidades de classes (específicos ou não da Enfermagem) também devem se ocupar deste tema, pois, em última instância, é a sua força política que deve gerar e determinar a força do CS.

\section{REFERÊNCIAS}

1. Rocha EM, Cunha JXP, Lira LSSP, Oliveira LB, Nery AA, et al. O papel do conselheiro municipal de saúde na fiscalização do orçamento público. Saúde debate. 2013;37(96):104-11.

2. Algebaile J. O papel dos conselhos de saúde no SUS. Fundação Oswaldo Cruz, 2011. [Internet] [acesso em 20 set 2012]. Disponível: http://www.retsus.epsjv. fiocruz.br/upload/42/Retsus42_EmRede.pdf

3. Gaio TC, Faria EM. Cidadania, participação e controle social: requisitos para efetivar o SUS. Texto Contexto Enferm. 2000;9(2):264-73.

4. Arantes CIS, Mesquita CC, Machado MLT, Ogata MN. O controle social no Sistema Único de Saúde: concepções e ações de enfermeiras da atenção básica. Texto Contexto Enferm. 2007;16(3):470-8.

5. Merhy EE, Onocko R, organizadores. Praxis en salud: un desafío para lo público. São Paulo: Hucitec; 1997.

6. Feuerwerker LCM. Além do discurso de mudança na educação médica: processos e resultados. São Paulo: Hucitec; 2002.

7. Feuerwerker LCM, Llanos CM, Almeida M. Educação dos profissionais de saúde na América Latina: teoria e prática de um movimento de mudança. São Paulo: Hucitec; 1999.

8. Rolim LB, Cruz RSBLC, Sampaio KJAG. Participação popular e o controle social como diretriz do SUS: uma revisão narrativa. Saúde debate. 2013;37(96):139-47. 
9. Lima LAO. Alternativas éticas ao neoliberalismo: as propostas de Rawls e Habermas. Lua Nova. 1993;(2829):335-50.

10. Fontes V. Sociedade civil. In: Pereira IB, Lima JCF, organizadores. Dicionário da Educação Profissional em Saúde. Rio de Janeiro: Escola Politécnica Joaquim Venâncio; 2009. [Internet] [acesso em 20 set 2012]. Disponível: http://www.epsjv.fiocruz.br/dicionario/ verbetes/socciv.html

11. Martins LM. As aparências enganam: divergências entre o materialismo histórico dialético e as abordagens qualitativas de pesquisa. 29 $9^{\text {a }}$. Reunião Anual da ANPED, GT 17: Filosofia da Educação; 2006. [Internet] [acesso em 30 jun 2012]. Disponível: http://www.eventos.uem. br/index.php/cipsi/2012/paper/viewFile/495/284.

12. Gil AC. Métodos e técnicas de pesquisa social. São Paulo: Atlas; 1999.

13. Martins ALX, Santos SMR. O exercício do controle social no Sistema Único de Saúde: a ótica do enfermeiro como membro do conselho local de saúde. Saúde soc. 2012;21(supl. 1):199-209.

14. Bravo MIS, Souza RO. Conselheiros de saúde e serviço social: luta política e trabalho profissional. Ser Social. 2002;10:15-27.

15. Gramsci A. Obras escolhidas. São Paulo: Martins Fontes; 1978.

16. Marx K. Teses sobre Feuerbach. In: Marx K, Engels F. Obras escolhidas. São Paulo: Alfa-Ômega; 1978. 